ISSN: 2224-0616

Int. J . Agril. Res. Innov. \& Tech. 5(2): 44-50, December, 2015 Available online at http:// www.ijarit.webs.com

\title{
DETERMINANTS OF AGRO PASTORALISTS' PARTICIPATION IN IRRIGATION SCHEME: THE CASE OF FENTALLE AGRO PASTORAL DISTRICT, OROMIA REGIONAL STATE, ETHIOPIA
}

\author{
Abdi Etafa Regassa
}

Received 19 September 2015, Revised 14 December 2015, Accepted 22 December 2015, Published online 31 December 2015

\begin{abstract}
This paper analyzed the factors determining participation in irrigation project on agro pastoral household and their perception towards the scheme. The study result depends on cross-sectional data collected from a sample of 144 households of which 72 irrigation users and 72 non-users using a combination of multistage, stratified and random sampling. The data were analyzed using descriptive statistics and logistic regression to assess factors that affect participation in irrigation. Result revealed that agro pastoralists do have medium to very strong perception towards different aspects of irrigation performance indicator variable. It is observed that among the variables in logistic regression age, sex, income, input use and participation in cooperative organization have affected participation significantly and positively, while, farm experience, distance to the district market, and total livestock unit, affected participation in irrigation significantly and negatively. The study has also substantiated that irrigation in the study area has significant role on income and recommend that it shall be great and rewarding if policy makers, designers, implementers, and any funding agencies with similar interest. Further, capitalize and scale up the project to achieve the development plan and objective.
\end{abstract}

Keywords: Irrigation, Income, Households, Participation, Logistic Regression

Adami Tulu Agricultural Research Center, P.O. box 35 Ziway, Ethiopia

*Corresponding author's email: abdrom.etafa@gmail.com (Abdi Etafa Regassa)

\section{Introduction}

Agriculture is still the pillar of the Ethiopian economy, which contributed $41.6 \%$ to GDP in 2009 (GTP, 2010). It also provides raw material to industrial sector, export items and is major source of employment for 84\% Ethiopia population (PASDEP, 2005). Cognizant to this fact, the country focused its development strategy, that is, Agricultural Development Led Industrialization (ADLI) on agriculture to transform the economy. ADLI aims for boosting agricultural productivity and improving the rural standard of living, which in turn increase the demand for goods, services and further lead to industrial development. One of the impetuses to achieve the agricultural policy objective is the promotion of irrigated agriculture and integrated water resource management of ADLI (1994).

According to Christine et al. (2007) and FAO/WFP (2006) in Ethiopia, there has been a revival of irrigation during the last decades in order to enhance rural development and food security. Given that 84 percent of the people employed in agriculture PASDEP (2005), developing this sector could help to reduce poverty and enhance food and livelihood security of the majority of the Ethiopian people. At the beginning of the 1970's, about 100 thousand hectares of land was estimated to be under modern irrigation in Ethiopia, about $50 \%$ of which was located in the Awash Valley (Wetterhall, 1972). According to Elimneh (2013), the Derg regime gave emphasis in development of large and medium irrigation schemes to mitigate drought and famine. The Ethiopian People Republic Democratic Front (EPRDF), the current regime, like its predecessors enthusiastic in developing irrigated agriculture. Thus, it has developed an irrigation policy that aims developing the huge irrigated agriculture potential for the production of food crops and raw materials needed for agro industries, in an efficient and sustainable basis and without degrading the fertility of the production fields and water resources base (MoWR, 1999).

Despite the fact, trends of agricultural growth in Ethiopia are heavily reliant on expansion of agricultural land (extensification) and limited intensification through irrigation. In the last three decades, the annual production increase for cereal, pulses and oil seeds as it is disaggregated in to productivity increase due to increase in land area. This clearly shows that average annual growth in production, mainly comes from cultivated land growth and little productivity growth; the average population growth of Ethiopia is growing at approximately $2.1 \%$ in the 
same period. The result shows production growth is far away below population growth; Given that majority of the population live in highland and marginal areas, the former pushes agriculture to encroach more and more to less productive, highly vulnerable to degradation and high gradient marginal land (Awulachew,2010). Irrigation and improved agricultural water management practice could provide opportunities to cope with impact of climatic variability enhance productivity per unit of land, increase the annual production volume significantly. The irrigation projects implemented provide a wide variety of information, services, and financial assistance; however, very little rigorous evaluation had been undertaking on the actual impact of irrigation programs on reducing poverty and enhancing the rural households' livelihood diversification. In addition, While the role of irrigation in poverty reduction has been studied more extensively in Asia, relatively little research has been done in Sub-Saharan Africa, where Ethiopia is belonged (Hussain and Hanjra, 2004).

Different scholars also argued that recurrent drought is the key factor that causes vulnerability of pastoralists in Ethiopia. Duguma (2013) stated that traditional coping and adaptation strategies of pastoralists in Ethiopia become increasingly insufficient to sustain local livelihoods during drought. The vulnerability of agro-pastoralist community must explain with reference to much broader socio-economic, political and environmental issues. Further, the government of Ethiopia is enhancing the contribution of irrigation towards the food and nutrition security strategy of the development policy to which the development of the Boset-Fentale irrigation project is one. Now a day, with double digit growth of Ethiopian economy and transformative plan of the government; aimed at enhancing productivity of agriculture to lead the economy and support the industry than serving as subsistence; it is focused on irrigation scheme development as an instrument. Because of the growing concern over food and livelihood security and an increasing trend in the occurrence of drought in the Oromia region, the regional government has planned and implemented to utilize the existing irrigation potential. Further, although a number studies were done in different corner of the country on the determinants of irrigation participation much of it is focused on small scale and no study was done on Fentalle irrigation; yet, little information is available and no works had been done so far on the proposed topic and at the study area.

Moreover, this could be further facilitated by examining how participation in irrigation project is determining the livelihood of rural dwellers to provide a clear way to the policy makers; improving systems for providing extension and technical support to smallholder irrigation users. Owing to the above-mentioned realities, this study focused on assessing determinants of participation in irrigation and agro pastoralists' perception towards the irrigation scheme. Therefore, the aim of this study is to understand factors affecting farmers' participation in Boset Fentale irrigation project and their perception to the project with the following research objectives:

1. To assess the determinant of household participation in irrigation.

2. To describe perception of agro-pastoralist about Fentale irrigation project.

\section{Methodology}

Fentale is located in the great Ethiopian mid rift valley under the east Shoa zonal administrative division of Oromia regional state crossed by the Kesem and Awash River. It is $193 \mathrm{~km}$ east of the capital Addis Ababa on the highway to Djibouti. It is boarded on the southeast by the Arsi Zone, on the southwest by Boset district, on the northwest by the Amhara Regional states, and on the northeast by the Afar Regional states. Fentale district located between $8^{\circ} 45^{\prime} \mathrm{N}$ to $39^{\circ} 50^{\prime} \mathrm{E}$ which is in tropical climatic zone. The approximate total area of Fentale District is $1340 \mathrm{Km}^{2}$ and Metehara town is the capital town and administrative center of the District. Fentalle district found in The Northern section of Oromia Rift system ranges in altitude from $1500 \mathrm{~m}$ $2000 \mathrm{~m}$. The major ethnic groups inhabited in Fentale district are Kereyu and Ittu Oromo's and few Somali ethnic minorities. Out of 18 kebeles located in Fentale district 11 are considered pure pastoralist (FDSEP, 2013). According to 22 years climate data of National Metrological Agency from 1989-2011 the District climate is Hot-semi Arid, characterized by step type of vegetation with less fall and more coarse grasses. The mean annual temperature and rainfall of Fentale district varies between $18^{\circ} \mathrm{C}$ and $34^{\circ} \mathrm{C}$ and 377 $\mathrm{mm}-742 \mathrm{~mm}$ respectively with mean annual rainfall of $572 \mathrm{~mm}$.

Sample was drawn from the two populations, participants and non-participants of irrigation. Multi- stage, stratified and random sampling technique was used. At primary selection, unit three study kebeles based on their distance to market and access to irrigation were selected. Finally, with the aid of simple random sampling 72 samples was drown from each stratum. Both group of study was selected from the same kebeles to reduce heterogeneity except for irrigation All information about irrigation water use, technical, socio economic and institutional factor and others relevant to the study were gathered from primary and secondary sources such as documents, study reports of development centers, district office and from resource centers. 
Data for this study were collected from households using a semi-structured interview schedule. In addition, discussion was held with key informants and focus group discussion to access detailed information. A FGD and key informant interview data were used to qualitatively support the study result and characterize the constraints. Analysis was done with the aid of (SPSS version 20 and STATA version 13). The qualitative data collected using key informant interviews, field observation, focus group discussion and oral histories were analyzed using narrative explanation and argument. Quantitative data were analyzed using different descriptive and inferential statistical tools specifically, means, percentages, frequencies distribution, standard deviation, test statistics and logistic regression analysis.

\section{Results and Discussion}

\section{Socioeconomic characteristics}

The socio economic characteristic of the surveyed household is summarized in Table 1. It shows that among the presented features; farm experience, education level, total livestock unit, frequency of extension contact per month, income from livestock and crop shows significant difference for participants and non-participants.

Table 1. Summary statistics and distribution of continues variables

\begin{tabular}{lcccccccc}
\hline \multirow{2}{*}{\multicolumn{1}{c}{ Variables }} & \multicolumn{2}{c}{ Participant } & \multicolumn{2}{c}{ Non-participant } & \multicolumn{2}{c}{ Total } & t & P-value \\
\cline { 2 - 9 } & Mean & SD & Mean & SD & Mean & SD & & \\
\hline Age & 35.98 & 10.2 & 35.43 & 9.24 & 35.70 & 9.74 & -0.34 & 0.73 \\
Farming experience & 7.66 & 4.82 & 10.13 & 5.45 & 8.90 & 5.27 & 2.88 & $0.004^{* *}$ \\
Edu. level & 1.69 & 2.83 & 1.01 & 2.13 & 1.35 & 2.52 & 1.62 & $0.10^{*}$ \\
Family size & 6.05 & 3.01 & 6.05 & 3.02 & 6.05 & 3.01 & 0.00 & 1.00 \\
Dependency ratio & 1.03 & .98 & 1.28 & .95 & 1.16 & .97 & 1.54 & 0.12 \\
TLU & 15.28 & 17.5 & 10.40 & 18.01 & 12.84 & 17.8 & 1.64 & $0.10^{*}$ \\
Farm size & 1.00 & 0.50 & .94 & .41 & .97 & .46 & .74 & 0.46 \\
Ext. freq.in Month & 2.15 & 1.97 & 1.61 & 1.70 & 1.88 & 1.86 & -1.75 & $0.08^{*}$ \\
Livestock Income & 9666.8 & 13792.4 & 6173.4 & 11127.7 & 7920.1 & 12609.6 & -1.67 & $0.09^{*}$ \\
Crop Income & $20,747.9$ & $30,388.8$ & $2,509.7$ & $1,067.7$ & $11,628.8$ & $24,470.6$ & -4.80 & $0.00^{* *}$ \\
Dist. to district & 23.71 & 11.39 & 24.1 & 11.31 & 23.94 & 11.31 & 0.23 & 0.81 \\
\hline
\end{tabular}

Source: computed from own survey, $2014^{*}{ }^{* * *}$ significant at $10 \%$, and $1 \%$ probability level , respectively

The average farming experience of the participants is 7.66 and it is 10.13 for nonparticipants. The test statistical analysis revealed that there is significant difference in farming experience between irrigation participants and non-participants at probability level of less than $1 \%$. Income from crop production is also significant at probability less than $1 \%$, with the mean annual income of 20,747.9 ETB1, for participants and 2,509.7 ETB for nonparticipant. The mean of education level, TLU and frequency of extension contact in a month is 1.69, 1.01; 15.28, 10.40 and 2.15, 1.61 for users and non-users, respectively. Further, the average income obtained from livestock is also different for the irrigation participants and nonparticipants it is 9,666.8 and 6,173.4 birr for users and non-users, respectively. The entire four variables revealed that there is significant difference between participants and nonparticipants at less than $10 \%$ probability level with relatively high mean in education level, TLU, and frequency of extension contact per month of user.

\section{Farmers' perception on the effect of irrigation}

In this study, respondents were asked about their perception on 7 (seven) researcher experience based selected irrigation performance indicators

1ETB 20.02 =1 USD during study period using five Likert-type scale, i.e. $5=$ very high, $4=$ high, 3=medium, $2=$ low and $1=$ very low. In addition, the mean perception of respondents on the irrigation were categorized as $1.00-1.80$ very low, 1.81-2.60 low, 2.61-3.40 medium, 3.41-4.20 high, 4.21-5.00 very high using the total mean score with equal interval of 0.8 unit. Accordingly, the frequency distribution and percentage response of the irrigation participant indicated that $51.39 \%$ responded that access to irrigation has strong effect on the productivity of farm and crop diversification, followed by $34.70 \%$ responding very strong. It is also reported that $30.56 \%$ of respondents perceived that irrigation has both medium and strong impact on enhancing livestock population, followed by poor with $19.44 \%$ implying that participation in irrigation has negative impact on livestock population. With regard to irrigation effect on reducing disease and increasing feed availability nearly $43.00 \%$ have medium perception followed by strong perception with $30.50 \%$ response rate. Attitude of farmers to irrigation management and compatibility to the farmers' knowledge and skill is $41.67 \%$ and $25.00 \%$ with medium to strong perception respectively. $45.80 \%$ and $30.56 \%$ of the response also indicated that the overall performance of irrigation scheme is very strong and medium respectively. 
The mean difference of the categories was tested for significances through chi square-test. As a result, there is a significant difference among the five-perception category group at less than $5 \%$ and $1 \%$ probability level for each performance indicators. Accordingly, respondents' attitude and perception of irrigation on farm productivity is very strong with the mean score of 4.21 , and less than $1 \%$ probability level of significance. It is also strong towards irrigation overall performance with mean score of 4.11 and less than $1 \%$ probability level. Perception level is medium for irrigation effect on livestock population, its effect on reducing the occurrence of disease and enhanced feed availability, management and compatibility, irrigation accessibility, and locally practiced rule and regulation of water management with mean score of $3.00,3.31,3.32,3.13$, and 3.17 at less than $5 \%$, $1 \%, 1 \%, 5 \%$ and $5 \%$ level of probability, respectively.

Table 2. Distribution of farmers perception towards irrigation effect on different aspects

\begin{tabular}{|c|c|c|c|c|c|c|c|c|c|c|c|c|c|}
\hline \multirow{2}{*}{ Indicators } & \multicolumn{2}{|c|}{ Very poor } & \multicolumn{2}{|c|}{ poor } & \multicolumn{2}{|c|}{ medium } & \multicolumn{2}{|c|}{ Strong } & \multicolumn{2}{|c|}{ Very strong } & \multirow{2}{*}{$\begin{array}{l}\text { mean } \\
\text { score }\end{array}$} & \multirow{2}{*}{$\chi^{2}$} & \multirow{2}{*}{$\overline{p-\text { value }}$} \\
\hline & $\mathrm{n}$ & $\%$ & $\mathrm{n}$ & $\%$ & $\mathrm{n}$ & $\%$ & $\mathrm{n}$ & $\%$ & $\mathrm{n}$ & $\%$ & & & \\
\hline $\begin{array}{l}\text { Effect on } \\
\text { productivity }\end{array}$ & - & - & - & - & 10 & 13.9 & 37 & 51.4 & 25 & 34.7 & 4.21 & 15.25 & $.000^{* *}$ \\
\hline $\begin{array}{l}\text { Effect on livestock } \\
\text { population }\end{array}$ & 9 & 12.5 & 14 & 19.4 & 22 & 30.6 & 22 & 30.6 & 5 & 6.9 & 3.00 & 16.19 & $.003^{* *}$ \\
\hline $\begin{array}{l}\text { Effect on feed and } \\
\text { disease }\end{array}$ & 5 & 6.9 & 6 & 8.3 & 31 & 43.0 & 22 & 30.6 & 8 & 11.1 & 3.31 & 37.02 & $.000^{* *}$ \\
\hline $\begin{array}{l}\text { Irrigation mgmt. } \\
\text { \& compatibility }\end{array}$ & 1 & 1.4 & 13 & 18.0 & 30 & 41.7 & 18 & 25 & 10 & 13.9 & 3.32 & 31.75 & $.000^{* *}$ \\
\hline $\begin{array}{l}\text { Irrigation } \\
\text { performance }\end{array}$ & 1 & 1.4 & 6 & 8.3 & 10 & 13.9 & 22 & 30.6 & 33 & 45.8 & 4.11 & 46.75 & $.000^{* *}$ \\
\hline $\begin{array}{l}\text { Accessibility of } \\
\text { irrigation }\end{array}$ & 7 & 9.7 & 14 & 19.4 & 23 & 31.9 & 19 & 26.4 & 9 & 12.5 & 3.13 & 12.44 & $.014^{*}$ \\
\hline $\begin{array}{l}\text { Cultural custom } \\
\text { and rules of water } \\
\text { mgmt. }\end{array}$ & 11 & 15.5 & 9 & 12.7 & 17 & 23.9 & 25 & 35.2 & 9 & 12.7 & 3.17 & 13.29 & $0.01^{*}$ \\
\hline
\end{tabular}

** , * significant at $1 \%$ and $5 \%$ level of significance

Determinant of participation in irrigation

Out of the 17 variables, eight of them were statistically significant in the model while the rest were not significant $(\mathrm{p}<0.10)$. The statistically significant variables include, age, sex, farm experience, natural logarithm (ln) of income, distance to the district market, total livestock unit, input use and participation in cooperative and local organization.

Table 3. Logit estimate of determinants of participation in irrigation scheme

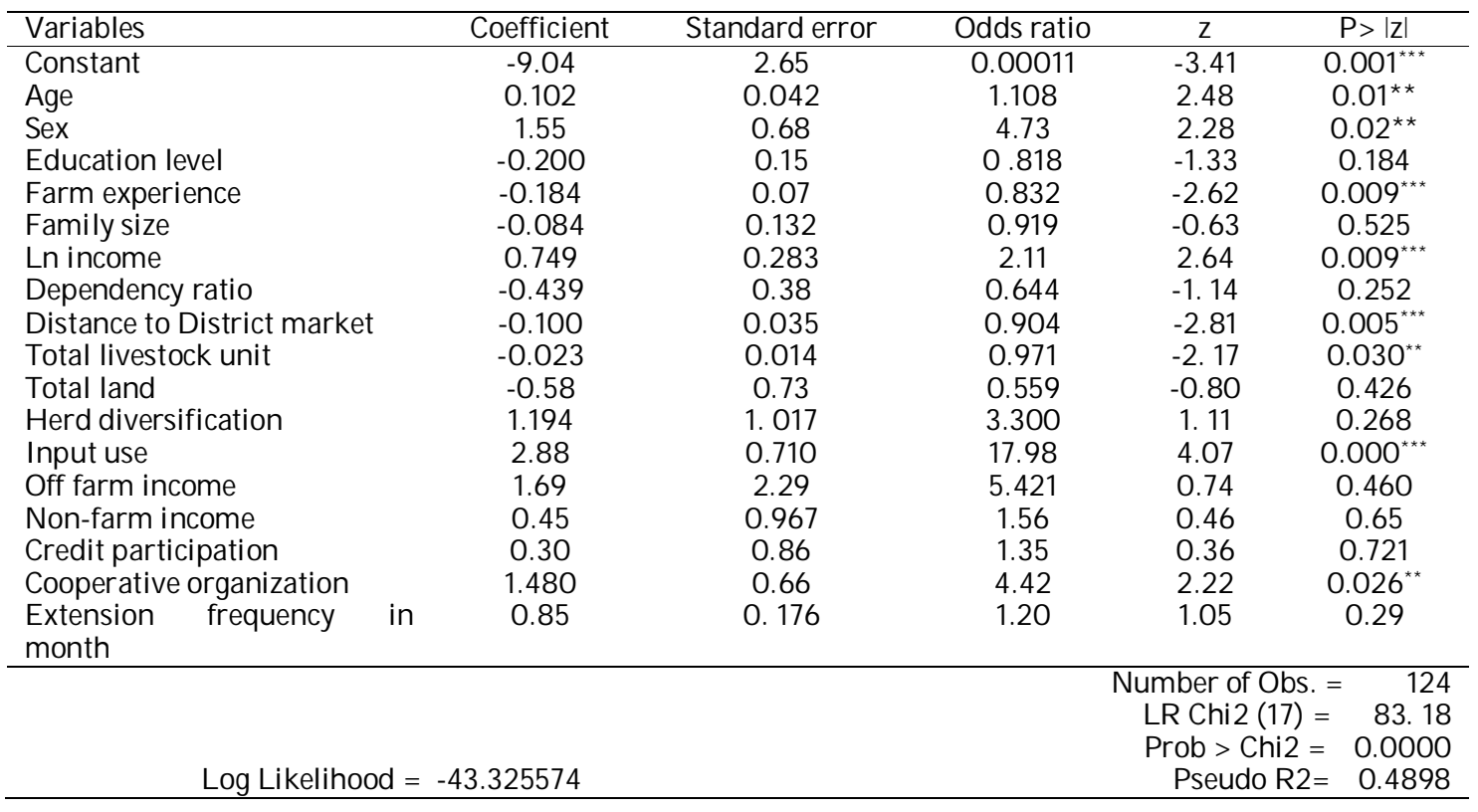

Source: model output. ${ }^{* *}$ Significant at $1 \%,{ }^{* *}$ significant at 5\% probability level 
AGE is significant at $\mathrm{p}<0.01$ level and related to farmers desire to participate in irrigation positively. The odds ratio of 1.10 indicates that other factors constant, as the age increases by one year the likelihoods of participation in irrigation as a source of income and livelihood increase by a factor of 1.1. it is probably due to that older household heads participate less in the agricultural wage labor market, thus, older farmers are expected to be less active and hence rely more on farm; and it is also related with better older farmers' resource endowment (land and livestock) than the youngsters. The result is against the study of Miknie (2005) and Ahmed et al. (2014). However, it is in line with the study conducted by Berhanu (2003) and Eshete (2007) which had indicated the positive and significant relation of age effect of livelihood.

SEX in this study, it was hypothesized to affect participation in irrigation positively. The model output also indicated that it is significant $(\mathrm{p}<0.05)$ and related to participation in irrigation positively. Other factors constant, the odds of 4.73 indicated that being male increases participation in irrigation by odd factor of 4.73 . It is likely due to that male-headed households hardly faced labour shortage for irrigation as well as rain fed farming due to physical, technological, socio-cultural, and psychological fitness of farm instrument to males than females. In addition, men and women have different access to resources and opportunities. This result supports the study of (Ellis, 2000; Asayehegn et al., 2012).

Farming experience: It was hypothesized positive. The model output however, indicate that farm experience negatively affected participation in irrigation at $p<0.01$ level. The odd ratio of 0.83 indicated that other factors constant, participation in irrigation increased by odd factor of 0.83 with a unit decrease in farm experience. The probable reason is that more experienced farmers in irrigation; accumulated capital and shifted their livelihood strategy, and income sources out of agriculture.

Farm income (ln income): The analysis result revealed that ln income affects participation in irrigation positively at $\mathrm{p}<0.01$ level. It was in line with the hypothesis. Citrus paribus, the odd ratio of 2.11 revealed that an increase in one unit of $l n$ income increases participation in irrigation by the odds of 2.11 units. The possible explanation is that those household who had sufficient gain from farm income: sale of crop, livestock, and their products are more likely to be irrigation participants than those who did not gained enough from farm income. This result supports the study by (Tsegaye and Bekele, 2010; Asayehegn et al., 2012).
Distance to the district market: In line to hypothesis, distance of respondents to district market, affect participation in irrigation negatively. The result is significant at $\mathrm{p}<0.01$ probability level. Other factors constant, participation in irrigation increases by odd factor of 0.9 units with a unit kilometre decrease in distance to district market, or participation in irrigation decreased by odd factor of 0.9 units as the distance increased by one kilometre. The probably reason is that participation is related to production of high value horticultural crops that are short in shelf life and easily perishable. The cumulative effect of Lack of good roads, with distance to market and perishability of crop would resulted in hesitancy to participate in irrigation. This result is consistent and in line with the study of (Taddesse et al., 2000; Mengesha 2008; Ahmed et al., 2014).

Total livestock unit: It was significantly affected participation. Assuming other factors constant, as the number of livestock owned decreases by one TLU, participation in irrigation increases by the odds of 0.97 . The result is statistically significant at $\mathrm{p}<0.05$ level. This is probably because more extensive (encroachingly) nature of irrigation in land use would likely result in shift from rangeland to farmland which would have a negative implication on livestock population. The study is in line and consistent with the hypothesis and study conducted by Boru et al., (2011) which reveals the negative relationship between numbers of livestock owned and total land area cultivated showing the difficulty of combining large livestock population with field cultivation.

Input use: In line to the hypothesis, use of input (improved seed, fertilizer, and chemical) had determined participation in irrigation positively at $1 \%$ probability level. Citrus paribus, being a user of an input increases participation by odd factor of 17.98 units. The probable reason is that better productivity through farm input use on irrigated land might make farmers to go for participation in irrigation farming. This suggests that those who are better off can afford to buy fertilizer/ HYVs and those who are poor may not. As a result, input users may produce more per unit area than non-users and can have access to large quantity of food and diversify income sources for accumulation.

Cooperative participation: This variable is found to be significant at $\mathrm{p}<0.05$ level to positively determine participation in irrigation. Assuming other factors constant, being a member of cooperative organization increases participation by odd factor of 4.42. Further, FGD result indicated that farmers participate in cooperative and local organization for self-help, 
accessing input, irrigation management and maintenance, and marketing. Cooperatives promote access to social capital in which mutual resource management and self-help increases. Such a positive impact of cooperative (Parrachino and Patrone, 2006) indicated that, to some extent, place farmers in relationships with others, which have the benefit of establishing trust and decreasing the transactions and monitoring costs. Additionally, a cooperative supply can provide a mechanism to assure appropriate allocation of scarce water under some institutional arrangements.

\section{Conclusion and Recommendation}

To sustain the progressive impacts of the project and to enable beneficiary households make an optimum use of the irrigation scheme and based on the empirical findings in this research, the following recommendation suggested.

Irrigation is an important driving tool to development effort to ensure better income if properly used. The study has substantiated that irrigation in the study area, has significant impact on income and productivity. It shall be great and rewarding if policy makers, designers implementers, and any funding agencies with similar interest further capitalise and scale up the project to achieve the development plan and objective. Farmers' participation in cooperatives organization showed significant impact in irrigation participation. In addition, lack of wellorganized WUAs in the area and objective rules and regulation had resulted in problem of canal management, distribution, and allocation in efficiencies in the community and misuse of water. It shall be encouraged if the concerned bodies well organize the water user group with developed concrete rule and regulation, and reduced the rivalries due to the common pool interest.

Lack of adequate experience in irrigation made agro-pastoralist to lack technical knowledge on irrigation agronomic practices. Further, little attention from research and development to the crop production and agronomic practices of agropastoralist observed. It shall be best if research and development interventions in the area focused on enhancing the technical skill and knowledge of agro pastoralist on crop production, pest management, and disease control through training, exchange visits, trial, and demonstration. Further, better insect pest, disease tolerant and adaptable crop varieties are essential for the study area. It shall be great if market intervention in terms of either looking to different outlet, value addition, and or organization into marketing cooperative with linking to union and frequent consumers would encourage participation. Further, an improvement in road access and transportation facilities would also facilitate improved marketing and thereby, participation. The endowment capacity and empowerment of women in agro pastoral society is by far low. It shall be better if all development intervention, capacity-building activity in the study area intended with enhancing the endowment, and empowerment of women so that their contribution in agriculture would practically realised as in other communities. Further, gender analysis in terms of both the intra and inter household is also encouraged so that empirical findings will be adequately available for any intervening agent to advocate the role of female agro pastoralists in the irrigation and capacity building.

\section{References}

ADLI. 1994. Agricultural Development Led Industrialization. Economic Development policy of Ethiopia. Addis Ababa, Ethiopia.

Ahmed, B., Haji, J. and Kedir, A. 2014 Effect of Small-scale Irrigation on the Farm Households' Income of Rural Farmers: The Case of Girawa District, East Hararghe, Oromia, Ethiopia. Asian J. Agric. Rural Dev. 4(3): 257-266.

Asayehegn, K., Yirga, C. and Rajan, S. 2012. Effect of small-scale irrigation on the income of rural farm households: The case of Laelay Maichew District, Central Tigray, Ethiopia. J. Agril. Sci. 7(1): 43-57.

Awulachew, S.B. 2010. Irrigation potential in Ethiopia: Constraints and opportunities for enhancing the system. With contributions from Erkossa T., and Namara R. IWMI p159.

Berhanu, D. 2003. Non-farm Employment and Farm Production of smallholder Farmers: A Study in Edja District of Ethiopia. MSC Thesis. School of Graduate Studies, Alemaya University.

Boru, D., Schwartz, M., Kam, M. and Degen, A. A. 2011. Cattle reduction and livestock diversification among Borana pastoralist in southern Ethiopia. Forthcoming paper in Nomadic Peoples. Commission for nomadic peoples. pp. 1-44. Online available at http:// www.whpress.co.uk/ NP.html.

Christine, J., Willibald, L., Dominik, R., Michael, H., Bekele, S. and Fitsum, H. 2007. Impact of irrigation on livelihood and food security in the modern Hare river irrigation scheme in Southern Ethiopia. pp. 210-222. Online available at http:/ / publications.iwmi.org/ pdf/ H044076. pdf

Duguma, D.W. 2013. Adaptation of pastoralists to climate variability: The case of the 
Karrayu pastoralists' community in the Upper Awash Valley of Ethiopia. MSc thesis. Department of Sociology and Human Geography, University of Oslo. p. 4.

Elimneh, L.A. 2013. Challenges and opportunities of irrigated crop production in Gedeb river catchment. Machakel Woreda, East Gojjam Zone. African J. Agril. Econ. Rural Dev. 1 (1): 008-022, Available online at www.internationalscholarsjournals.org.

Ellis, F. 2000. Rural Livelihoods and Diversity in Developing Countries. Oxford University Press, Oxford. p.32

Eshete, B. 2007. Livelihood Strategies of Smallholder Farmers and Income Poverty in draught prone areas: The case of Gena- Bosa woreda, SNNPRS. MSc Thesis. School of Graduate Studies, Haramaya University.

FAO/WFP, 2006. Crop and Food Supply Assessment Mission to Ethiopia. Online available http:/ / www. who.int/ hac/ crises/ eth/ sitreps/ Ethiopia fao Feb06.pdf.

FDSEP. 2013. Fentalle District Socio-economic profile: district background information. 35p. (Unpublished).

GTP (Growth and Transformation Plan) 2010. Growth and Transformation Plan, Ministry of Finance and Economic Development of Federal Democratic Republic of Ethiopia, Addis Ababa, Ethiopia.

Hussain, I. and Hanjra, M. 2004. Irrigation and poverty alleviation: Review of the empirical evidence. Irrig. Drain. 53 (1): 1-15.

Mengesha, T. 2008. Small-scale irrigation scheme utilization and farmers willingness to pay for irrigation water: The case of Bosha-01 irrigation scheme in Central Oromia. MSc Thesis. School of Graduate Studies, Haramaya University. 154p.

Miknie, H. 2005. Dimensions and determinants of poverty in pastoral areas of Eastern Ethiopia: The Case of Shinile Zone Somli National Regional State. MSc thesis. Graduate studies, Alemaya University. 125p.

MoWR, 1999. Ethiopia Water Resources Management Policy. Ministry of Water, Irrigation \& Energy (MoWR), Government of Ethiopia, Addis Ababa, Ethiopia.

Parrachino, I. and Patrone, S.Z 2006. Cooperative Game Theory and its Application to Natural, Environmental, and Water Resource Issues; World Bank, Development Research Group, Sustainable Rural and Urban Development Team, Washington, D.C.

PASDEP (Plan for Accelerated and Sustained Development to End Poverty), 2005. FDRE 2005/6-2009/ 10, Addis Ababa, Ethiopia.

Taddesse, B. Admassie, A. and Croppenstdent, A. 2000. The impact of agricultural extension on farm productivity, Ethiopian J. Agril. Econ. 4(1): 23-47.

Tsegaye, G. and Bekele, W. 2010. Farmers' perceptions of land degradation and determinants of food security at Bilate Watershed, Southern Ethiopia. Ethiopian J . Appl. Sci. Tech. 1(1): 49- 62.

Wetterhall, H. 1972. Government and land in Ethiopia. Ministry of Land Reform and Administration, Addis Ababa, Ethiopia. 